\title{
Triglyceride associated polymorphisms of the APOA5 gene have very different allele frequencies in Pune, India compared to
} Europeans

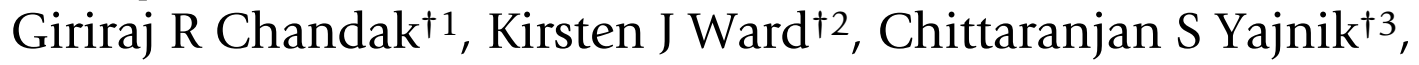 \\ Anand N Pandit ${ }^{4}$, Ashish Bavdekar ${ }^{4}$, Charu V Joglekar ${ }^{3}$, Caroline HD Fall ${ }^{5}$, \\ P Mohankrishna1, Terence J Wilkin ${ }^{6}$, Bradley S Metcalf6, Michael N Weedon ${ }^{2}$, \\ Timothy M Frayling ${ }^{2}$ and Andrew T Hattersley*2
}

\begin{abstract}
Address: ${ }^{1}$ Genome Research Group, Centre for Cellular and Molecular Biology, Hyderabad, India, ${ }^{2}$ Institute of Biomedical and Clinical Science, Peninsula Medical School, Exeter, UK, ${ }^{3}$ Diabetes Unit, King Edward Memorial Hospital and Research Centre, Pune, India, ${ }^{4}$ Department of Pediatrics, King Edward Memorial Hospital and Research Centre, Pune, India, ${ }^{5}$ Medical Research Council, Epidemiology Resource Centre, Southampton, UK and ' ${ }^{6}$ epartments of Endocrinology and Metabolism, Peninsula Medical School, Plymouth, UK

Email: Giriraj R Chandak - chandakgrc@ccmb.res.in; Kirsten J Ward - kjward@pms.ac.uk; Chittaranjan S Yajnik - csyajnik@hotmail.com; Anand N Pandit - kemhrc@pn2.vsnl.net.in; Ashish Bavdekar - bavdekar@vsnl.com; Charu V Joglekar - joglekar@pn2.vsnl.net.in; Caroline HD Fall - chdf@mrc.soton.ac.uk; P Mohankrishna - mohanp@ccmb.res.in; Terence J Wilkin - terence.wilkin@phnt.swest.nhs.uk; Bradley S Metcalf - brad.metcalf@pms.ac.uk; Michael N Weedon - michael.weedon@pms.ac.uk; Timothy M Frayling - tim.frayling@pms.ac.uk; Andrew T Hattersley* - andrew.hattersley@pms.ac.uk

* Corresponding author †Equal contributors
\end{abstract}

Published: 10 October 2006

BMC Medical Genetics 2006, 7:76 doi:10.1 I86/147|-2350-7-76

This article is available from: http://www.biomedcentral.com/l47/-2350/7/76

(c) 2006 Chandak et al; licensee BioMed Central Ltd.

This is an Open Access article distributed under the terms of the Creative Commons Attribution License (http://creativecommons.org/licenses/by/2.0), which permits unrestricted use, distribution, and reproduction in any medium, provided the original work is properly cited.
Received: 08 June 2006

Accepted: 10 October 2006

\begin{abstract}
Background: The APOA5 gene variants, $-\mathrm{I} \mid 3 \mathrm{IT}>\mathrm{C}$ and SI9W, are associated with altered triglyceride concentrations in studies of subjects of Caucasian and East Asian descent. There are few studies of these variants in South Asians. We investigated whether the two APOA5 variants also show similar association with various lipid parameters in Indian population as in the UK white subjects.
\end{abstract}

Methods: We genotyped 557 Indian adults from Pune, India, and 237 UK white adults for - I I 3 I T>C and SI $9 \mathrm{~W}$ variants in the APOA5 gene, compared their allelic and genotype frequency and determined their association with fasting serum triglycerides, total cholesterol, HDL and LDL cholesterol levels using univariate general linear analysis. APOC3 Sst polymorphism was also analyzed in 175 Pune Indian subjects for analysis of linkage disequilibrium with the APOA5 variants.

Results: The APOA5 -II3IC allele was more prevalent in Indians from Pune (Pune Indians) compared to UK white subjects (allele frequency $20 \%$ vs. $4 \%, p=0.0000 \mathrm{I})$, whereas the $19 \mathrm{~W}$ allele was less prevalent $(3 \%$ vs. $6 \% p=0.00 \mathrm{I} 5)$. Patterns of linkage disequilibrium between the two variants were similar between the two populations and confirmed that they occur on two different haplotypes. In Pune Indians, the presence of - II3IC allele and the I9W allele was associated with a $19 \%$ and $15 \%$ increase respectively in triglyceride concentrations although only - II 3 IC was significant $(p=0.0003)$. This effect size was similar to that seen in the UK white subjects. Analysis of the APOC3 Sstl polymorphism in 175 Pune Indian subjects showed that this variant is not in appreciable linkage disequilibrium with the APOA5 - I I 3 I T >C variant $\left(r^{2}=0.07\right)$.

Conclusion: This is the first study to look at the role of APOA5 in Asian Indian subjects that reside in India. The $-\mathrm{I}$ I 3 IC allele is more prevalent and the 19W allele is less prevalent in Pune Indians compared to UK Caucasians. We confirm that the APOA5 variants are associated with triglyceride levels independent of ethnicity and that this association is similar 
in magnitude in Asian Indians and Caucasians. The - II3IC allele is present in 36\% of the Pune Indian population making it a powerful marker for looking at the role of elevated triglycerides in important conditions such as pancreatitis, diabetes and coronary heart disease.

\section{Background}

The APOA5 gene was first identified as a conserved DNA sequence $27 \mathrm{~Kb}$ proximal to the Apolipoprotein cluster of APOA1, APOA4 and APOC3 on chromosome 11q23 [1]. It is an important regulator of triglycerides, as established by both genetic manipulation in animals [1] and a large number of genetic studies in man [1-8]. To date, most studies of the APOA5 gene have been conducted in cohorts of Caucasian subjects and have shown that two haplotypes, defined by the SNPs -1131 T>C and S19W, are independently associated with triglyceride concentrations. The association between $-1131 \mathrm{~T}>\mathrm{C}$ and triglyceride concentrations is likely to be explained by linkage disequilibrium (LD) with SNPs in the neighbouring APOC3 gene whilst there is no LD between S19W and APOC3 variants [9]. Supporting this, the $-1131 \mathrm{C}$ allele is associated with lower APOA5 concentrations and higher triglyceride concentrations whereas the 19W allele is associated with higher APOA5 and higher triglyceride concentrations, relative to subjects homozygous for the less common allele $[10,11]$. The majority of published reports have observed the minor allele frequency for both these variants to be approximately $6 \%$ in Caucasian populations [1-8]. However, the frequencies vary considerably across different ethnic groups. The prevalence of $-1131 \mathrm{C}$ allele varies between 6.4\% in American Caucasian males [5] and 34\% in the Japanese population [12], whilst the 19W allele frequency varies between $0.1 \%$ in a Chinese population [13] and $15.8 \%$ in Hispanic males [5]. The reported size of effect of the less common alleles on triglyceride concentration varies in different cohorts from different races $[2,5,12-15]$. However, most studies show a $15-30 \%$ increase in triglyceride concentrations with the inheritance of the minor allele at these polymorphisms and there is no clear evidence that ethnic origin determines the size of the increase.

There is limited data available on the APOA5 gene variants in the Asian Indian population. The only study to date is on Asian Indians residing in Singapore and shows a minor allele frequency of $23 \%$ at $-1131 \mathrm{~T}>\mathrm{C}$ and $<3 \%$ for the S19W polymorphisms [13]. No study has been conducted on the role of APOA5 in Asian Indians residing in India. It is important to understand the genetic contribution to triglyceride metabolism in Asian Indians since they have higher triglyceride concentrations compared to Caucasians relative to their BMI and these differences can occur as early as 10 years old [16].
In this study, we have compared the allele frequency of the $-1131 \mathrm{~T}>\mathrm{C}$ and S19W variants in Pune Indians and UK white subjects and examined the size of their effect on fasting triglycerides and other lipid parameters in these two populations.

\section{Methods \\ Subjects}

The Asian Indian adult cohort comprised of 557 parents from the Pune children study, which is a consecutive birth cohort from KEM Hospital, Pune [17]. This cohort consisted of subjects of Indo European descent from Maharashtra in Western India. The Institutional Ethics Committee approved the study following the Indian Council of Medical Research guidelines for research on human subjects. All subjects gave written informed consent to participate in the study. The UK white adult cohort included 237 parents from the Plymouth EarlyBird study, which is a non-intervention prospective study of school age children and their parents [18]. This cohort complies with the Declaration of Helsinki, and Local Research Ethics Committee approval was obtained early in 1999. Subjects with diabetes on fasting and 2-hour OGTT criteria were excluded. Clinical details of subjects are given in table 1 .

\section{Genotyping APOA5 and APOC3 variants}

The UK white subjects were genotyped for -1131T>C polymorphism using the RFLP assay with $2 \mathrm{U}$ of MseI (New England Biolabs, UK), as previously described [7] while, genotyping of Pune Indian individuals was performed using a tetra-primer based PCR method, previously described [19]. Both the cohorts were genotyped for S19W using an RFLP protocol with $7 \mathrm{U}$ of EagI, as previously described [7]. The results of tetra primer assay for $1131 \mathrm{~T}>\mathrm{C}$ were validated by RFLP analysis in $~ 10 \%$ (50/ 524 ) of randomly chosen Pune Indian samples. In an attempt to investigate the extent of $\mathrm{LD}$ between the APOA5 -1131T>C and the APOC3 SstI variants, we genotyped the APOC3 SstI SNP in 175 Pune Indians by RFLP assay using $10 \mathrm{U}$ of SstI [7] and validated the results in 15\% (30/175) samples by sequencing.

\section{Quality control measures}

Two independent individuals scored the agarose gels to determine the genotype and any discrepancies were resolved by sequencing. Rare homozygotes were confirmed by re-genotyping and $10 \%$ of randomly selected samples were re-genotyped with a genotyping accuracy of 
Table I: Clinical characteristics of Pune Indian individuals and UK white subjects.

\begin{tabular}{lcc}
\hline & Pune Indians & UK Whites \\
\hline $\mathrm{N}$ & 557 & 237 \\
$\%$ male & 45 & 52 \\
Age $(\mathrm{Yrs})$ & $36(32-40)$ & $34(31-38)$ \\
BMI $\left(\mathrm{kg} / \mathrm{m}^{2}\right)$ & $22.3(19.7-24.9)$ & $26(23.2-28.6)$ \\
Total Cholesterol (mg/dl) & $155(133-184)$ & $187(168-215)$ \\
HDL-Cholesterol (mg/dl) & $40(32-49)$ & $53(46-64)$ \\
LDL-Cholesterol (mg/dl) & $94(77-118)$ & $113(93-139)$ \\
Triglycerides $(\mathrm{mg} / \mathrm{dl})$ & $85(59-119)$ & $84(62-117)$ \\
Fasting glucose $(\mathrm{mg} / \mathrm{dl})$ & $88(80-96)$ & $85(79-88)$ \\
Fasting insulin (mg/dl) & $34(22-50)$ & $53(42-75)$ \\
\hline
\end{tabular}

Pune Indian individuals (adults from the Pune Children Study) and UK white subjects (adults from the Plymouth EarlyBird study).

Data presented as median (interquartile range); BMI; Body Mass Index, HDL; High Density Lipoprotein, LDL; Low Density Lipoprotein.

$>99 \%$ for all the variants. Overall, genotypes were obtained for all the UK white adult samples and 94\% ( $\mathrm{n}=$ 524) of Pune Indian adults.

\section{Statistics}

Allele and genotype frequencies were calculated for both SNPs using chi-squared analyses. Hardy-Weinberg Equilibrium (HWE) was tested by comparing the observed with the expected genotype frequency using Chi-square analysis. The LDMAX function of GOLD software was used to calculate the linkage disequilibrium between the two SNPs in APOA5 gene and between the APOA5 $1131 \mathrm{~T}>\mathrm{C}$ SNP and APOC3 SstI variant. Association analysis between the genotype and various lipid parameters was performed using univariate general linear model analysis in SPSS (SPSS 11.0). Continuous parameters were log transformed where necessary before conducting any analysis. Genotypes were tested for association with potential covariates of triglyceride concentrations and if significantly associated, genotype-triglyceride comparisons were adjusted. Since the homozygotes for the less common allele were rare $(<0.05)$ for both the APOA5 polymorphisms, the heterozygotes and the less common allele homozygotes were pooled for further analysis: $((\mathrm{TC}+\mathrm{CC})$ and $(\mathrm{SW}+\mathrm{WW}))$. The independent T-Test was used to determine the standardized effect of these variants on triglyceride concentrations with the presence or absence of the less common allele. Regression analysis was performed to determine the independent effect of different variables on triglyceride concentrations. Although statistical tests used logged variables where necessary, we present untransformed means for consistency with previous studies.

\section{Results and discussion}

We present the first study investigating the common APOA5 variants and their association with lipid concen- trations in Asian Indian adults, residing in Pune, India, as compared to UK white adults.

\section{Ethnic differences in the allele frequency of the $-I|3| T>C$ and the SI9W polymorphisms}

A total of 761 individuals comprising 524 Pune Indian adults and 237 UK white adults were successfully genotyped for the $-1131 \mathrm{~T}>\mathrm{C}$ and $\mathrm{S} 19 \mathrm{~W}$ polymorphisms in the APOA5 gene. The less common allele at $-1131 \mathrm{~T}>\mathrm{C}$ variant was significantly more prevalent than the S19W polymorphism in the Pune Indians (20\% vs. 3\% respectively), whereas the allele frequency for both SNPs was comparable in UK white subjects (4\% and $6 \%$ respectively: table 2 ). We observed a marked difference in the minor allele frequency at both SNPs between the Pune Indians and UK white subjects (table 2 ). The $-1131 \mathrm{C}$ allele is more prevalent in the Pune Indian subjects compared to the UK white subjects (allele frequency $20 \%$ vs. $4 \%$, p = 0.00001), while the $19 \mathrm{~W}$ allele is less prevalent in the Pune Indians (allele frequency $3 \%$ vs. $6 \% \mathrm{p}=0.0015)$. Approximately, $1 / 3^{\text {rd }}$ $(36 \%)$ of Indian subjects carried at least one copy of the less common allele at $-1131 \mathrm{~T}>\mathrm{C}$ compared to only $8 \%$ of UK white individuals but only $5 \%$ of Pune Indian individuals carry the $19 \mathrm{~W}$ allele compared to $11 \%$ UK white subjects.

The allele frequencies in Pune Indians are consistent with the only previous study of individuals of Indian descent from Singapore (23\% for $1131 \mathrm{C}$ allele and $<3 \%$ for $19 \mathrm{~W}$ allele) [13]. This follows a similar pattern in other Asian ethnic groups such as Japanese, Malaysian and Chinese which also have a higher prevalence of the $-1131 \mathrm{C}$ allele [13] in contrast to Caucasian populations where the two variants have similar minor allele frequencies [5].

Linkage disequilibrium analysis did not show association between the two variants in either of the cohorts $\left(\mathrm{r}^{2}=\right.$ 
Table 2: Prevalence of APOA5 gene variants - I I I IT>C and SI $9 \mathrm{~W}$ in Asian Indians and UK white subjects.

\begin{tabular}{|c|c|c|c|c|c|c|c|c|c|c|}
\hline \multirow{2}{*}{ SNP } & \multicolumn{5}{|c|}{-|| $3 \mid T>C$} & \multicolumn{5}{|c|}{ SI9W } \\
\hline & TT & $\mathrm{TC}$ & $\mathrm{CC}$ & Carrier* Frequency $(95 \% \mathrm{Cls})$ & $\begin{array}{l}\text { Less common allele } \\
\text { Frequency }(95 \% \mathrm{Cls})\end{array}$ & SS & SW & WW & $\begin{array}{l}\text { Carrier* Frequency } \\
(95 \% \mathrm{Cls})\end{array}$ & $\begin{array}{l}\text { Less common allele } \\
\text { Frequency }(95 \% \mathrm{Cls})\end{array}$ \\
\hline Pune Indians $(n=524)$ & 336 & 170 & 18 & $0.36(0.32-0.40)$ & $0.20(0.17-0.22)$ & 497 & 27 & 0 & $0.05(0.03-0.07)$ & $0.03(0.02-0.04)$ \\
\hline UK whites $(n=237)$ & 218 & 19 & 0 & $0.08(0.05-0.11)$ & $0.04(0.02-0.06)$ & 210 & 26 & 1 & $0.11(0.07-0.15)$ & $0.06(0.04-0.08)$ \\
\hline$P$ value & & & & & $<0.00001$ & & & & & 0.0015 \\
\hline
\end{tabular}

Asian Indians (adults from the Pune Children Study) and UK white subjects (adults from the Plymouth EarlyBird study).

$P$ values are calculated for differences in genotype frequencies between Pune Indians and UK white subjects. *Carrier frequency indicates individuals carrying at least one copy of the less common allele at either polymorphism. Neither population showed any deviation from HWE for either polymorphism $(p>0.05)$.

0.005; in Pune Indians and $\mathrm{r}^{2}=0.007$ in UK whites), indicating that the two variants fall on different haplotypes in Indians as they do in other populations.

\section{Effect of the APOA5 variants on triglyceride concentrations and other lipid parameters in the Pune Indian and $U K$ white subjects}

The effect of each APOA5 polymorphism in each group of subjects is shown in table 3 . The presence of the $-1131 \mathrm{C}$ allele (TC and CC subjects combined) is associated with higher triglyceride concentrations in the Pune Indians by 0.25 standard deviations ( $95 \%$ CI, 0.12-0.39; $\mathrm{p}=0.0003$ ) and in the Plymouth EarlyBird study UK whites by 0.5 standard deviations ( $95 \% \mathrm{CI}, 0.11-0.89 ; \mathrm{p}=0.01$ ) relative to TT subjects. The difference in size effect between the two groups of subjects is not significant.

The presence of the 19W allele was associated with raised triglyceride concentrations in the Pune Indians by 0.25 standard deviations (95\% CI, -0.11-0.60; $\mathrm{p}=0.17$ ), although this did not reach significance, and in the Plymouth EarlyBird study UK whites by 0.41 standard deviations (95\% CI, 0.10-0.73; p = 0.008). The $15-19 \%$ increase in the fasting triglyceride concentration associ- ated with the inheritance of less common alleles at either of the two polymorphisms in the Pune Indians is a very similar effect size to that seen in previous studies of Caucasian subjects. This suggests that the main difference between Pune Indians and UK whites is the allele frequency rather than how much they alter the triglyceride concentration. We also performed all analyses whilst correcting for age and sex but the $\mathrm{p}$ values and effect sizes changed very little because genotypes were not associated with age or sex. There were no associations between the two APOA5 variants and either HDL, LDL or total cholesterol in either the Pune Indian or UK white subjects, although this may be due to lack of power if the effects on these lipid parameters is less than the effects on triglycerides.

We next assessed the extent of linkage disequilibrium between the APOA5 -1131T>C SNP and the APOC3 SstI SNP in Pune Indians and observed $D^{\prime}$ and $\mathrm{r}^{2}$ values between these two SNPs of 0.41 and 0.07 respectively. This suggests that the highly significant association between the APOA5 -1131T>C variant and triglyceride concentrations is not driven by LD with the APOC3 SstI SNP. Further work is needed to assess more comprehen-

Table 3: Association of serum triglyceride concentrations and other lipid parameters (mg/dl) with APOA5 genotype for - I I 3 IT $>C$ and SI9W.

\begin{tabular}{|c|c|c|c|c|c|c|c|c|c|c|}
\hline & & \multicolumn{5}{|c|}{-|| $3 \mid T>C$} & \multicolumn{4}{|c|}{ SI9W } \\
\hline & & TT & $\mathrm{CT}$ & $\mathrm{CC}$ & Effect on lipid (SD)* & P Value & SS & $s W+W W$ & Effect on lipid (SD) & P Value \\
\hline \multirow[t]{2}{*}{ Triglycerides } & Pune Indians & $91.5(3.1)$ & 110.1 (4.3) & $106.0(13.1)$ & $0.25(0.12,0.39)$ & 0.0003 & $97.2(2.5)$ & $1 \mid 4.0(11.0)$ & $0.25(-0.11,0.60)$ & 0.17 \\
\hline & UK whites & $95.3(3.8)$ & $125.3(12.6)$ & - & $0.50(0.11,0.89)$ & 0.01 & $94.4(3.7)$ & $123.0(12.1)$ & $0.4 I(0.10,0.73)$ & 0.008 \\
\hline \multirow[t]{2}{*}{ HDL } & Pune Indians & $41.4(0.7)$ & $41.2(0.9)$ & $37.2(2.9)$ & $-0.03(-0.21,0.15)$ & 0.73 & $4 I . I(0.6)$ & $41.7(2.4)$ & $0.07(-0.32,0.47)$ & 0.71 \\
\hline & UK whites & $55.8(0.95)$ & $54.2(2.3)$ & - & $-0.03(-0.49,0.44)$ & 0.91 & $56.1(0.96)$ & $51.9(2.5)$ & $-0.33(-0.72,0.07)$ & 0.10 \\
\hline \multirow[t]{2}{*}{ LDL } & Pune Indians & $96.8(1.8)$ & $101.6(2.5)$ & $100.1(7.6)$ & $0.11(-0.08,0.29)$ & 0.25 & $98.2(1.5)$ & $103.5(6.3)$ & $0.16(-0.24,0.56)$ & 0.44 \\
\hline & UK whites & II $5.5(2.4)$ & $123.9(5.5)$ & - & $0.26(-0.21,0.73)$ & 0.27 & II $5.5(2.3)$ & 121.1 (8.3) & $0.05(-0.35,0.46)$ & 0.79 \\
\hline \multirow[t]{2}{*}{ Total Cholesterol } & Pune Indians & $156.6(2.0)$ & $164.6(2.7)$ & $158.6(8.5)$ & $0.19(0.01,0.36)$ & 0.04 & $158.8(1.6)$ & $167.9(7.1)$ & $0.25(-0.15,0.64)$ & 0.22 \\
\hline & UK whites & $189.8(2.5)$ & $202.6(5.4)$ & - & $0.36(-0.11,0.83)$ & 0.13 & $190.0(2.5)$ & $197.1(8.6)$ & $0.13(-0.27-0.53)$ & 0.52 \\
\hline
\end{tabular}

Values are given as mean (SE), units (mg/dl); $P$ values are based on linear regression analysis. SD = standard deviations. *Effect on triglycerides in Pune Indians is for CC+CT individuals versus TT individuals and for both studies are based on logged values. There are no $-\mathrm{II} 3 \mathrm{I} C \mathrm{C}$ individuals in the UK white population. 
sively the role of other common variations in the APOC3 gene in Indian subjects.

\section{Comparison of associations between genotype and phenotype variables on triglyceride concentrations in the Pune Indians and the UK white subjects}

Regression analysis to determine the effect of different variables on triglycerides concentrations is shown in table 4. Except for the S19W variant, all the variables including age, sex, BMI, fasting glucose and insulin and $-1131 \mathrm{~T}>\mathrm{C}$ were significantly associated with triglyceride concentrations in the Pune Indian individuals. Sex and BMI were most strongly correlated with triglyceride concentrations in the Pune Indians $\left(\mathrm{r}^{2}=0.13\right.$ and $\mathrm{r}^{2}=0.12$ respectively, $\mathrm{p}$ $<0.001$ ) whilst sex, BMI and fasting insulin were all strongly correlated with triglyceride concentrations in the UK whites $\left(\mathrm{r}^{2}=0.12, \mathrm{r}^{2}=0.14\right.$ and $\mathrm{r}^{2}=0.16$ respectively, $\mathrm{p}$ $<0.001)$. In both cohorts, the APOA5 alleles are associated with variation in triglyceride concentrations.

\section{Conclusion}

We conclude that the $-1131 \mathrm{C}$ allele in APOA5 is considerably more common in Indo Europeans from Maharashtra (Pune Indians) than in UK white subjects and has a similar impact on triglyceride concentration. Conditions associated with hypertriglyceridaemia, such as pancreatitis, insulin resistance, type 2 diabetes and coronary heart disease are highly prevalent in Asian Indian populations. The relatively high $-1131 \mathrm{C}$ allele frequency within Pune Indian subjects will mean it is possible to assess whether a life-long increase in triglyceride concentrations as a result of inheriting this variant increases the risk of these disorders [20].

\section{Abbreviations}

APOA5 - Apolipoprotein A5

Table 4: Separate effects of different variables on triglyceride levels for the Asian Indians and UK whites.

\begin{tabular}{|c|c|c|c|c|}
\hline \multirow[t]{2}{*}{ Variable } & \multicolumn{2}{|l|}{ Pune Indians } & \multicolumn{2}{|l|}{ UK whites } \\
\hline & Adjusted $\mathrm{R}^{2}$ & $P$ value & Adjusted $\mathrm{R}^{2}$ & $P$ value \\
\hline Age & 0.08 & $<0.001$ & -0.004 & 0.84 \\
\hline Sex & 0.13 & $<0.001$ & 0.12 & $<0.001$ \\
\hline BMI & 0.12 & $<0.001$ & 0.14 & $<0.001$ \\
\hline Fasting Glucose & 0.014 & 0.003 & 0.00001 & 0.32 \\
\hline Fasting Insulin & 0.06 & $<0.001$ & 0.16 & $<0.001$ \\
\hline HDL-Cholesterol & 0.07 & $<0.001$ & 0.17 & $<0.001$ \\
\hline LDL-Cholesterol & 0.08 & $<0.001$ & 0.13 & $<0.001$ \\
\hline Total Cholesterol & 0.23 & $<0.001$ & 0.21 & $<0.001$ \\
\hline-|| $3 \mid T>C$ & 0.023 & 0.0003 & 0.009 & 0.015 \\
\hline SI9W & 0.002 & 0.17 & 0.025 & 0.008 \\
\hline All variables together & 0.26 & $<0.001$ & 0.31 & $<0.001$ \\
\hline
\end{tabular}

Asian Indians (adults from the Pune Children Study) and UK whites (adults from the Plymouth EarlyBird Study).
APOA1 - Apolipoprotein AI

APOA4 - Apolipoprotein AIV

APOC3 - Apolipoprotein CIII

SNPs - Single Nucleotide Polymorphisms

HDL - High Density Lipoprotein

LDL - Low Density Lipoprotein

OGTT - Oral Glucose Tolerance Test

LD - Linkage Disequilibrium

CV - Coefficient of Variation

HWE - Hardy Weinberg Equilibrium

CI - Confidence Intervals

BMI - Body Mass Index

\section{Competing interests}

The author(s) declare that they have no competing interests.

\section{Authors' contributions}

GRC, KJW, CSY, ATH, TMF all designed the genetic study; most of the practical work was carried out by KJW, GRC and PMK. The Pune Children's study was designed by CSY, ANP, AB, CHDF and CVJ. The Plymouth EarlyBird study was designed by TJW, CVJ, BSM \& MNW and TMF carried out the analysis of the data. GRC, KJW, TMF and ATH wrote the first draft of the paper with all authors contributing to and approving the final version.

\section{Acknowledgements}

This work was funded by the Wellcome Trust and through a studentship for KJW by Diabetes Research and Education Trust (DIRECT) and The University of Exeter, UK. The funding for the Pune Children's Study is also through Wellcome trust. ATH is a Wellcome Trust Career Leave Research Fellow. PMK is funded by the Wellcome Trust and GRC by the Centre for Cellular and Molecular Biology, an organisation under Council for Scientific and Industrial Research, Government of India.

\section{References}

I. Pennacchio LA, Olivier M, Hubacek JA, Cohen JC, Cox DR, Fruchart JC, Krauss RM, Rubin EM: An apolipoprotein influencing triglycerides in humans and mice revealed by comparative sequencing. Science 200I, 294:169-173.

2. Aouizerat BE, Kulkarni M, Heilbron D, Drown D, Raskin S, Pullinger CR, Malloy MJ, Kane JP: Genetic analysis of a polymorphism in the human apoA-V gene: effect on plasma lipids. J Lipid Res 2003, 44: II67-II73.

3. Horinek A, Vrablik M, Ceska R, Adamkova V, Poledne R, Hubacek JA: T-I|3I-->C polymorphism within the apolipoprotein AV 
gene in hypertriglyceridemic individuals. Atherosclerosis 2003 , 167:369-370.

4. Martin S, Nicaud V, Humphries SE, Talmud PJ: Contribution of APOA5 gene variants to plasma triglyceride determination and to the response to both fat and glucose tolerance challenges. Biochim Biophys Acta 2003, 1637:217-225.

5. Pennacchio LA, Olivier M, Hubacek JA, Krauss RM, Rubin EM, Cohen JC: Two independent apolipoprotein A5 haplotypes influence human plasma triglyceride levels. Hum Mol Genet 2002, I I:303।-3038.

6. Ribalta J, Figuera L, Fernandez-Ballart J, Vilella E, Castro Cabezas M, Masana L, Joven J: Newly identified apolipoprotein AV gene predisposes to high plasma triglycerides in familial combined hyperlipidemia. Clin Chem 2002, 48: 1597-1600.

7. Talmud PJ, Hawe E, Martin S, Olivier M, Miller G], Rubin EM, Pennacchio LA, Humphries SE: Relative contribution of variation within the APOC3/A4/A5 gene cluster in determining plasma triglycerides. Hum Mol Genet 2002, I I:3039-3046.

8. Vrablik M, Horinek A, Ceska R, Adamkova V, Poledne R, Hubacek JA: Ser 19-->Trp polymorphism within the apolipoprotein AV gene in hypertriglyceridaemic people. J Med Genet 2003, 40:el 05.

9. Olivier M, Wang X, Cole R, Gau B, Kim J, Rubin EM, Pennacchio LA: Haplotype analysis of the apolipoprotein gene cluster on human chromosome II. Genomics 2004, 83:912-923.

10. Dallinga-Thie GM, van Tol A, Hattori AH, van Vark-van der Zee LC, Jansen $\mathrm{H}$, Sijbrands EJ, on behalf of the DALI study group: Plasma apolipoprotein $\mathbf{A 5}$ and triglycerides in type $\mathbf{2}$ diabetes. Diabetologia 2006, 49: I505-I5II.

II. Vaessen SF, Schaap FG, Kuivenhoven JA, Groen AK, Hutten BA, Boekholdt SM, Hattori H, Sandhu MS, Bingham SA, Luben R, Palmen JA, Wareham NJ, Humphries SE, Kastelein JJ, Talmud PJ, Khaw KT: Apolipoprotein av, triglycerides and risk of future coronary artery disease in apparently healthy men and women; the prospective epic-norfolk population study. J Lipid Res 2006.

12. Nabika T, Nasreen S, Kobayashi S, Masuda J: The genetic effect of the apoprotein AV gene on the serum triglyceride level in Japanese. Atherosclerosis 2002, 165:201-204.

13. Lai CQ, Tai ES, Tan CE, Cutter J, Chew SK, Zhu YP, Adiconis X, Ordovas JM: The apolipoprotein A5 locus is a strong determinant of plasma triglyceride concentrations across ethnic groups in Singapore. J Lipid Res 2003.

14. Austin MA, Talmud PJ, Farin FM, Nickerson DA, Edwards KL, Leonetti D, McNeely MJ, Viernes HM, Humphries SE, Fujimoto WY: Association of apolipoprotein A5 variants with LDL particle size and triglyceride in Japanese Americans. Biochim Biophys Acta 2004, 1688:1-9.

15. Baum L, Tomlinson B, Thomas GN: APOA5-II3 I T>C polymorphism is associated with triglyceride levels in Chinese men. Clin Genet 2003, 63:377-379.

16. Whincup PH, Gilg JA, Papacosta O, Seymour C, Miller G], Alberti KG, Cook DG: Early evidence of ethnic differences in cardiovascular risk: cross sectional comparison of Brisitsh South Asian and white children. BMJ 2002, 324:625-626.

17. Yajnik CS, Fall CH, Vaidya U, Pandit AN, Bavdekar A, Bhat DS, Osmond $\mathrm{C}$, Hales $\mathrm{CN}$, Barker DJ: Fetal growth and glucose and insulin metabolism in four-year-old PCS children. Diabetic Medicine 1995, 12:330-336.

18. Wilkin TJ, Metcalf BS, Murphy MJ, Kirkby J, Jeffery AN, Voss LD: The relative contributions of birth weight, weight change, and current weight to insulin resistance in contemporary 5-yearolds: the EarlyBird Study. Diabetes 2002, $51: 3468-3472$

19. Ward KJ, Shields B, Knight B, Salzmann MB, Hattersley AT, Frayling TM: Genetic variants in Apolipoprotein AV alter triglyceride concentrations in pregnancy. Lipids Health Dis 2003, 2:9.

20. Davey Smith G, Ebrahim S: 'Mendelian randomization': can genetic epidemiology contribute to understanding environmental determinants of disease? Int J Epidemiol 2003, 32:I-22.

\section{Pre-publication history}

The pre-publication history for this paper can be accessed here:

http://www.biomedcentral.com/1471-2350/7/76/prepub
Publish with Bio Med Central and every scientist can read your work free of charge

"BioMed Central will be the most significant development for disseminating the results of biomedical research in our lifetime. "

Sir Paul Nurse, Cancer Research UK

Your research papers will be:

- available free of charge to the entire biomedical community

- peer reviewed and published immediately upon acceptance

- cited in PubMed and archived on PubMed Central

- yours - you keep the copyright
BioMedcentral 